\title{
El niño como pequeño director en la Red. Exploración de tres webs interactivas infantiles sobre educación mediática
}

\author{
Sánchez Carrero, Jacqueline \\ Universidad de Sevilla \\ http://dx.doi.org/10.12795/AdMIRA.2010.01.16
}

\section{Resumen:}

La Red provee a padres y maestros de una gran cantidad de recursos multimedia en pro del aprendizaje del niño. No obstante, no existen muchos portales en idioma español que oferten actividades, especialmente para los niños, que tengan que ver con el universo audiovisual en todas sus fases. Estos tres portales que presentamos, son de factura estadounidense e inglesa y muestran, en un entorno amigable, la manera como se construye el documento audiovisual. Con su interpretación en castellano esperamos contribuir a la difusión de la educación para los medios con un enfoque comprensible para los pequeños directores.

Palabras clave: niños en la web, cine y TV, realización audiovisual, educación mediática.

\section{El pequeño director en la Red}

Pocos recursos en la Red sirven de escenario al propio niño para vivenciar el mundo audiovisual. Queremos animar a padres y maestros a que entren de un modo entusiasta y accesible al mundo de la producción y realización audiovisual desde la propia web. Hemos seleccionado tres portales muy originales, actuales y destinados especialmente a niños menores de 11 años. Ellos son: Film Street, Zimmer Twins y Wildlife Filmmaker. Todas son factibles de navegar, con un poco de ayuda, y en compañía del niño que será el usuario final.

\section{1.- Film Street: la calle que enseña el mundo del cine}

Film Street es un portal realizado en el Reino Unido por Atticmedia y el apoyo de First Light Films, empresa dedicada a la educación cinematográfica infantil. Es uno de los sitios didácticos especialmente creado para niños menores de 11 años cuya misión es enseñar el mundo audiovisual de una manera sencilla y entretenida. El diseño virtual para niños y adolescentes es una actividad que aúna arte e inteligencia pues han de mostrarse contenidos interesantes con formas atractivas para el pequeño internauta. 
El objetivo de este portal es el aprendizaje sobre la industria del cine, tanto desde el punto de vista del espectador como de la realización. Y es por esto último por lo que se convierte en uno de los pocos sitios interactivos con un entorno amigable sobre estudios audiovisuales. Ha sido un sitio ganador de múltiples premios como el BIMA 2006 (British Interactive Media Association), el Mejor Proyecto Internacional en el European E-Learning Awards, el Yahoo "Find of the Year" en la categoría de educación (2007), y cuenta con una nominación al premio Bafta Interactivo otorgado por la Academia Británica de las Artes Cinematográficas y de la Televisión.

La ilustración, la animación y la interactividad son las marcas de identidad del portal. Y es que la interactividad es un factor determinante en la web 2.0. Tal como señalan Revuelta y Pérez en el libro Interactividad en los entornos de formación on-line (2009), la interactividad es una suerte de diálogo entre la persona y un software determinado a través del medio electrónico. Y es ya un mecanismo esperado por los usuarios de la Red en cualquiera de sus niveles. En este caso el niño puede elegir un personaje determinado para que lo conduzca a los distintos lugares. O también puede escoger caminar a lo largo de la calle del cine -Film Street- para entrar a los distintos apartados: Estudio de Cine, Animación, Sala de Cine, Vestuario, Academia de Cine y Biblioteca. Veamos parte por parte cada uno de sus apartados:

1.- Film Studios (Estudio de Cine). Aquí Julia le invitará a entrar al mundo de las cámaras, la iluminación, los efectos especiales, el sonido y la edición. Si pincha en e Cámaras y Luces entonces otro personaje, la directora Shehla, le indica que su función es explicarles a los actores cómo tienen que actuar y dónde han de situarse para que los focos de iluminación y los ángulos de cámaras sean correctos. Si pincha sobre la cámara de estudio aparecen imágenes reales que representan los principales tipos de planos: close up, plano medio o plano corto. Si oprime otros elementos interactivos como por ejemplo el foco de luz, leerá sobre la importancia de la iluminación en el mundo del cine. Si elige el micrófono con la pértiga, encontrará datos sobre el sonido y el micrófono para exteriores también conocido como “boom”. 


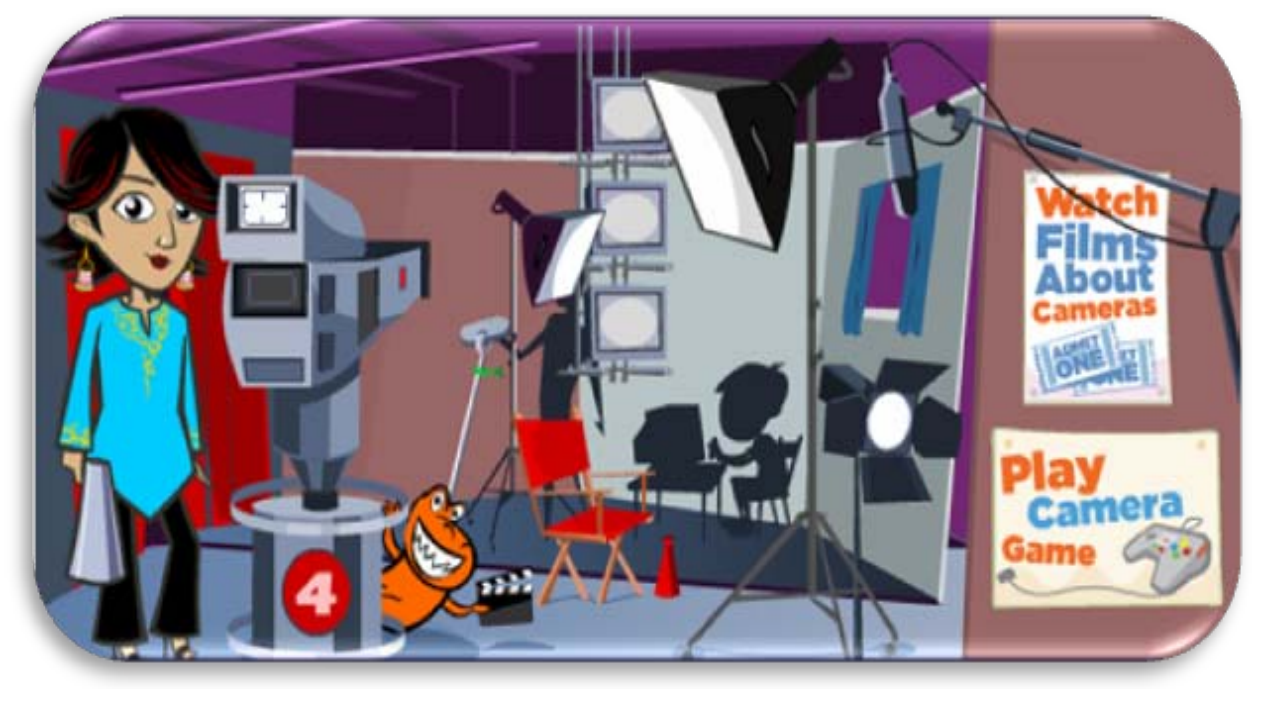

Al salir de allí puede entrar en el Cartel de cine que le invita a ver películas relacionadas con el tema de la cámara. Este icono del cartel aparece en todos los apartados y está fijado en la pared. Al entrar verá una franja donde elegirá entre tres escenas de películas, las cuales podrá accionar manejando el control de vídeo. En la primera el niño debe contar el número de planos que se realizan con la cámara, en la segunda película ha de observar los cambios de cámara en relación con la música, y en la tercera, se muestra la magia de la iluminación en una escena de suspenso. Todas son de muy corta duración.

Si sale, puede pinchar en otro cartel llamado Juega con la cámara. Es, a nuestro juicio, la actividad más interesante de todo el portal y la más atractiva encontrada en la Red. ¿Por qué? Porque en ella el niño puede convertirse en un verdadero realizador de televisión eligiendo los planos o movimientos a su gusto. Lógicamente, obtendrá distintos resultados según dicha elección. Shehla le explicará que puede crear una escena de suspenso según los distintos ángulos de cámara que seleccione. ¡Comienza el juego! Tiene a su disposición tres cámaras y el visor -especie de monitor- donde podrá visionar la imagen que está siendo grabada, es decir, la que verá el telespectador finalmente. Basta con oprimir "record" y empieza la emoción porque se inicia la grabación. Puede revisar el producto final, salvarlo - grabarlo- o repetir la experiencia. 


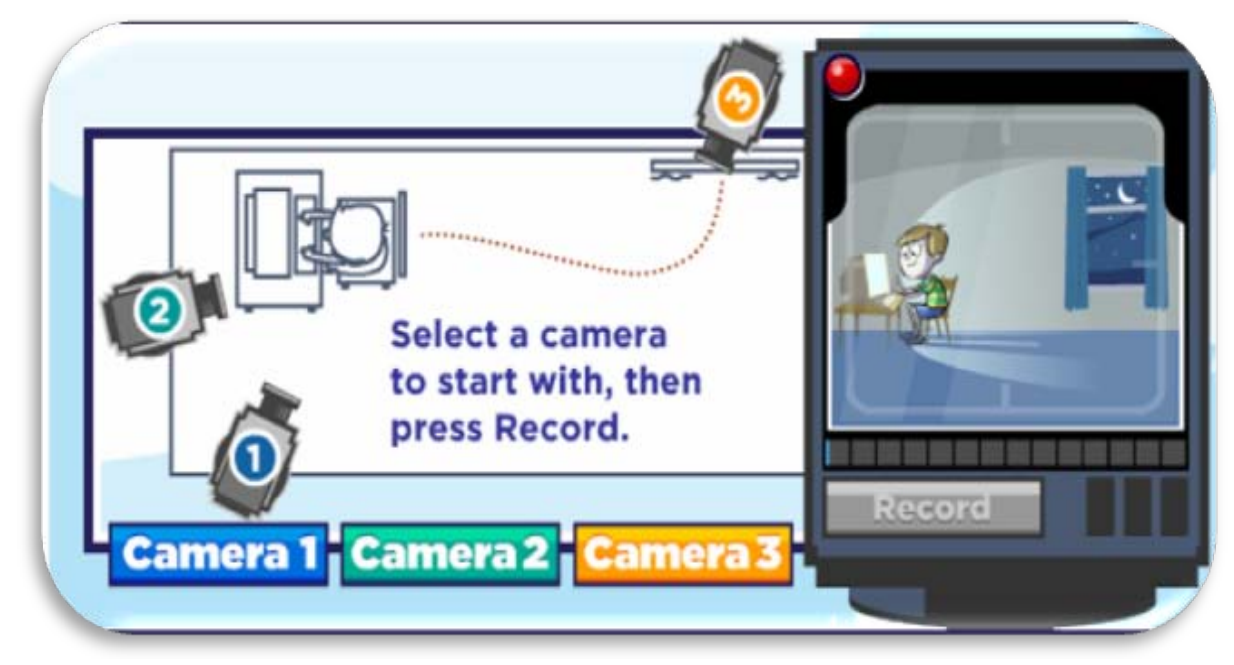

Si entra en Efectos Especiales, Bob se identificará como el amigo que le acompañará en esa sección. Pinchando en los distintos elementos interactivos podrá ver una fotografía con efectos de “ojos rojos”, imágenes congeladas o seres voladores. Al igual que en la sección anterior puede decidir “ir al cine” y ver tres escenas de películas con efectos especiales, identificar cortes de escena o transiciones, y también ver cómo aparecen o desaparecen personajes. La parte lúdica aporta la magia a este segmento pues al pinchar en Play Special FX Game el niño podrá cambiar el chroma key -o background de la escena- con un personaje en movimiento. Igualmente puede grabar y visionar luego el resultado de su juego.

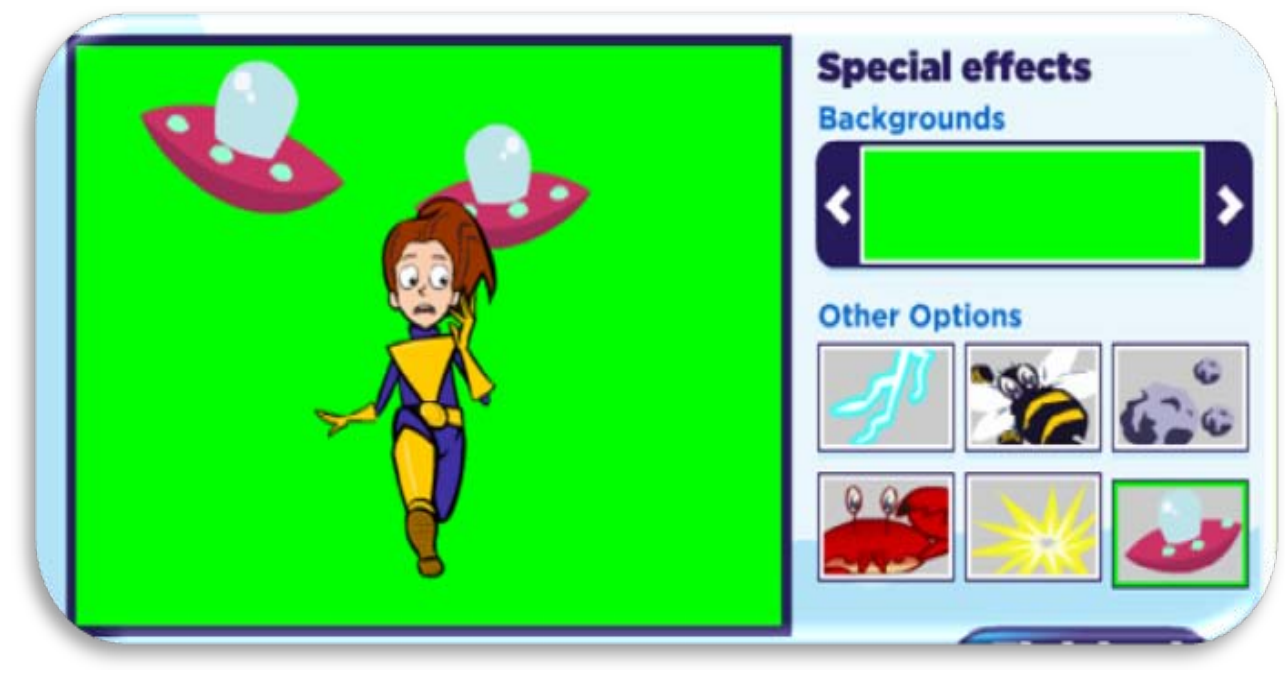

Otro de los segmentos más significativos de este portal es la sección, dentro de Film Studio, dedicada a la edición y los efectos de sonido, es decir, a la postproducción. Jim es el amigo que le mostrará ese mágico mundo del montaje. Si pincha en el ordenador le dirá que en la línea de tiempo -o Timeline- se ubican los clips de vídeo y la banda de 
sonido para la edición. Si oprime la ilustración que semeja a una mesa de mezclas, Jim le explicará que con la banda sonora se puede hacer llorar o reír al público. Lo mismo ocurrirá si escoge la cinta de reel (sonido). El juego del cartel de películas refleja lo que significa la continuidad en una escena real, los cambios que se pueden producir en la edición y la emoción que transmite la música, según la atmósfera que escoja en esta fase de postproducción.

2.- Film Academy (Academia de Cine). Aquí la guionista Fay le llevará por llevará por el mundo de la escritura para cine, comenzando por el Story Board y siguiendo con otras características básicas para esta actividad. En el Cartel de cine el niño será motivado a escribir un guión sobre su propia experiencia, visitará los alrededores de su casa o escuela para buscar inspiración como escritor y también verá la historia del Story Board -antes estudiado- convertida en película. El juego que ofrece este apartado es sumamente útil para animar al niño a escribir guiones. Se trata de una colección de ideas a las que puede tener acceso pinchando en el cartel del mismo nombre -Collect Story Ideas. Primero escogerá una idea principal, después un par de personajes y por último el entorno o ambientación en la cual desarrollará su historia. Luego, puede seleccionar entre varios un elemento para darle un toque más personal, como por ejemplo, unos globos, una pelota o un bote de pintura. Al pinchar en “finalizar” obtendrá todos los elementos en un álbum -imprimible- para dar vida a esa primera idea obtenida con la ayuda del portal. El padre o maestro puede descargar de esta web, formatos útiles para la elaboración del Story Board y el guión, entre otros.

3.- Cinema. Dave le recibe y le anima a “cliquear” en los posters cinematográficos para ver diferentes trailers. También puede seleccionarlos de un listado que comprende films de diversos géneros: fantasía, ciencia ficción, comedia, romance, aventura, drama, documentales y animación, atendiendo a los tramos de edad: 5 a 7, 7 a 9 y 9 a 11 años. Finalmente el pequeño usuario puede leer o incluso escribir una reseña sobre una de las películas. El último cartel guarda una sorpresa o actividad secreta a la que sólo tiene acceso si cumple todas las anteriores.

4.- Costume (Vestuario). Leroy es un diseñador de trajes. Le indicará que si pincha en algunos atuendos podrá entender la importancia del vestuario y del maquillaje en el mundo audiovisual, ya sea que se trate de una cinta de carácter histórico o actual. En el Cartel de cine se muestra cómo los niños pueden caracterizar personajes héroes o 
villanos a través de las prendas del vestuario y del arte del maquillaje. En el juego que proponen el usuario puede construir él mismo, contrareloj, el vestuario según sea el tipo de personaje que le pidan.

5.- Animatión. Aquí Joey, el experto, le revelará sus secretos acerca de la los tipos de animación: stop motion o cuadro a cuadro, la que se obtiene a través del ordenador y la que encaja en el método tradicional del dibujo. Los trailers muestran hermosas historias animadas en 2D y 3D. El juego invita al niño a construir su propia animación a través de la web. ¡Puede hacer bailar a un oso o a un robot! En una línea de tiempo podrá mover las extremidades de la figura, y cambiar de posición las manos y las piernas al ritmo de la música. Al final puede grabar la corta animación, tal como en los casos anteriores.

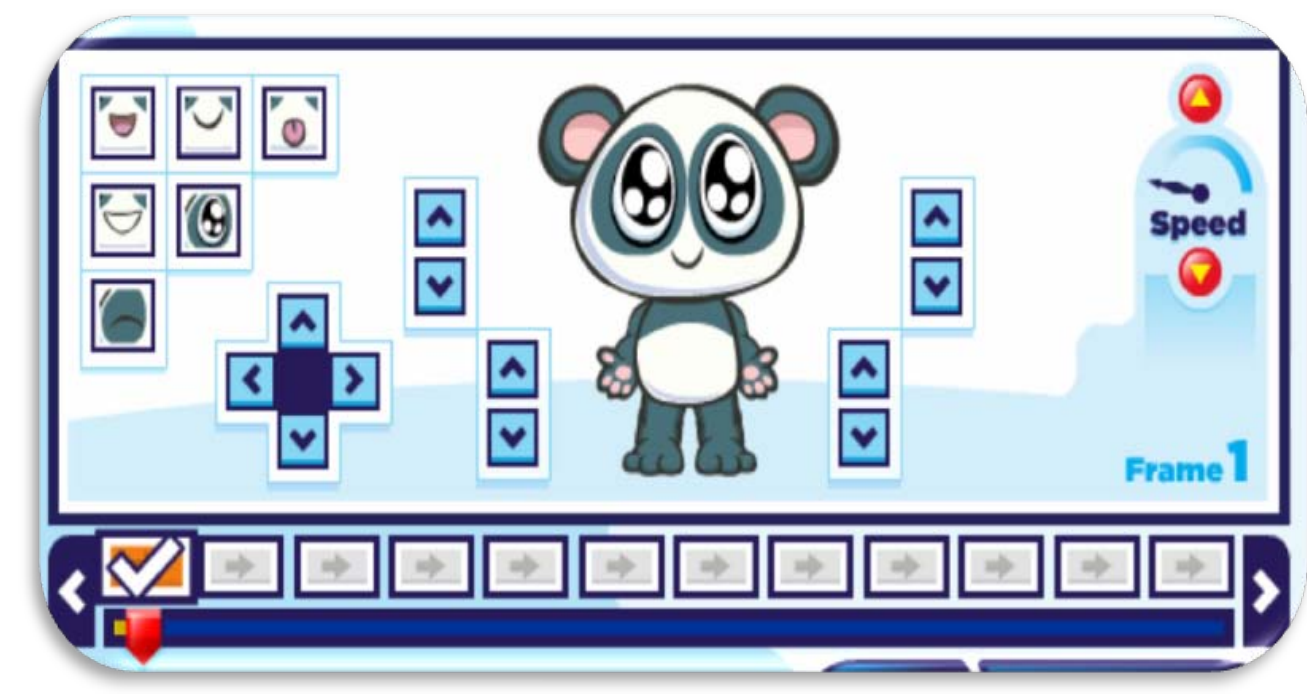

6.- Library (Biblioteca). Es un fondo informativo sobre películas documentales, musicales, de ciencia ficción... y ofrece además artículos relacionados con el "detrás de la cámara” de distintos films. Finalmente, obsequian al internauta un glosario de términos bastante completo clasificado alfabéticamente.

\section{2.- Zimmer Twins: las aventuras de dos hermanos y su gato}

Zimmer Twins enseña a los pequeños cibernautas a realizar su propia película a partir de imágenes animadas pre-establecidas. El sitio pertenece a Qubo, una red de televisión estadounidense destinada a los más pequeños y que está expandiéndose por los medios 
digitales. El lema del portal es: "¿Qué pasó después? ¡Tú decides!”. Con ello empujan al usuario a escoger las siguientes escenas de una historia que ya ha comenzado o a construir la suya propia eligiendo las que más le atraigan. Dos hermanos -Edgar y Evay su gato llamado “13” son los personajes principales de las secuencias narrativas llenas de humor y aventura. La fase de edición es la contribución más importante de este sitio web.

En un entorno sorprendentemente similar al de un software de edición real, el niño cuenta con tres elementos fundamentales: un monitor donde visionará el resultado de su película; el proyecto, donde dispone de animaciones, sonidos, efectos y rótulos; y una Línea de Tiempo o Timeline, el espacio donde finalmente va a arrastrar los clips y ordenarlos en la secuencia en la que desee siempre que tenga sentido. Así, para comenzar sólo tiene que elegir entre ver una película editada por otros usuarios, la cual puede comentar o incluso "reeditar”, o puede optar por hacer una nueva.

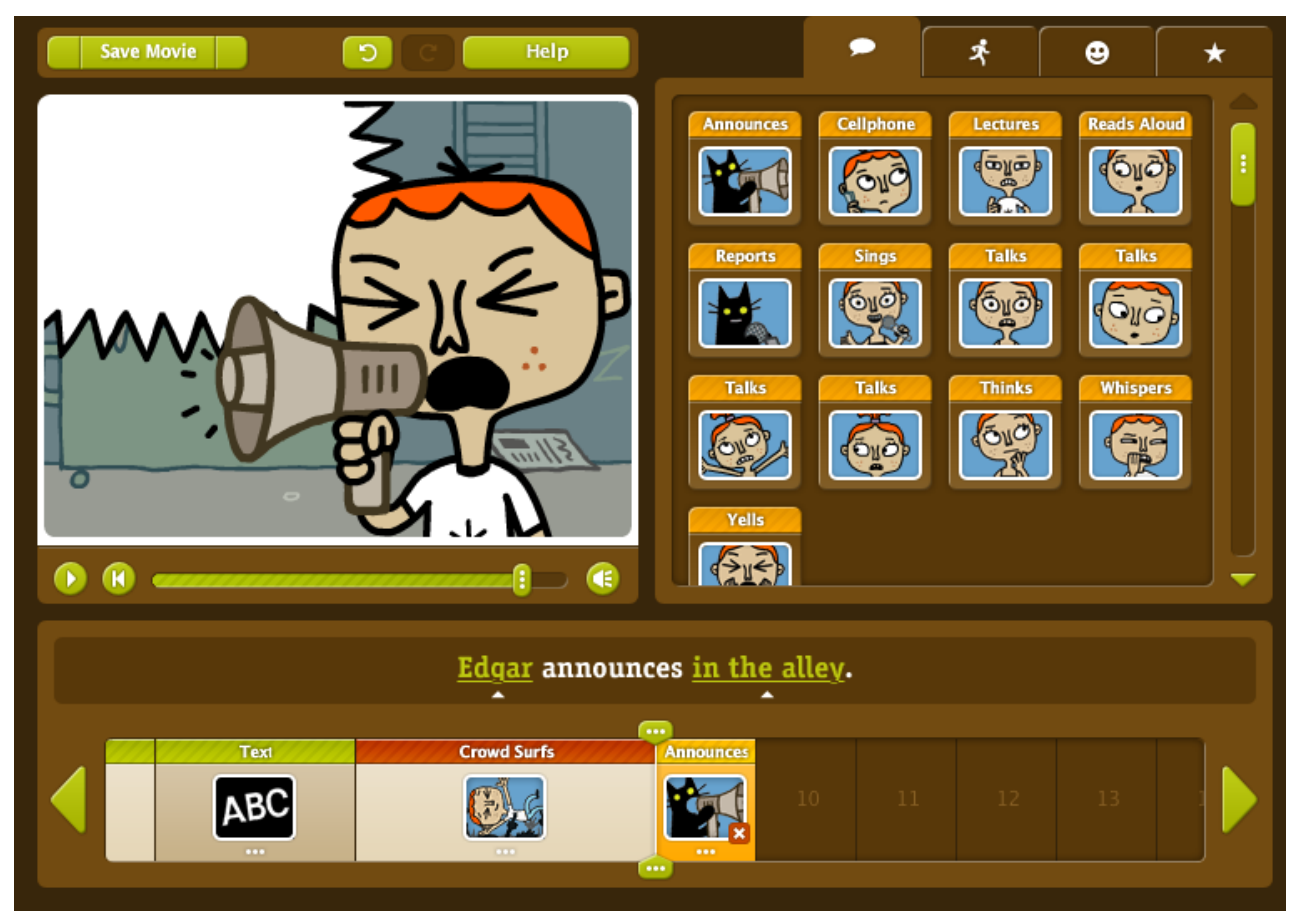

Si decide "hacer una película” aparecerá el entorno de edición. En el monitor puede visionar el progreso de su trabajo. De la ventana del proyecto puede elegir el material que bajará hasta la línea de tiempo. Puede escoger escenas a las que agregar textos, es decir, dispone de un "bocadillo" para escribir lo que quiera expresar su personaje. Tiene a su disposición distintas escenas con sonido relacionadas con temas activos tales como: risas, celebraciones, carreras, caídas, bailes, escondites, etc. La siguiente pestaña le 
ofrece escenas de sus personajes pero transmitiendo alguna emoción: aburrimiento, confusión, felicidad, sorpresa, entre otras. Finalmente, en la última pestaña encontrará imágenes de apoyo con la finalidad de utilizarlas como transición entre escenas. Se trata de un recurso útil para el inicio, el final, los títulos de crédito o para señalar el paso del tiempo.

En la Línea de Tiempo el portal le brinda la oportunidad de escoger entre muy variadas posibilidades de ambientación: cuevas, bosques, parques, jungla, entorno urbano o background de ciencia ficción. De esta forma el niño cuenta con todos los elementos de imagen y sonido necesarios para practicar en la Red y convertirse en todo un editor audiovisual. Al igual que en el anterior portal el pequeño director puede grabar su cortometraje y dejarlo en la web para ser visionado por otros.

\section{3.- Wildlife Filmmaker: director de documentales}

Nathional Geographic, es una organización reconocida por dedicarse a la naturaleza y a la difusión de la geografía en general. Llama la atención un portal dedicado a los usuarios más jóvenes en el cual puede convertirse en un director de documentales sobre la vida de la fauna y flora. El sitio web ofrece la oportunidad de grabar el producto final y generar una dirección electrónica para que familiares y amigos disfruten del trabajo audiovisual.

De los tres portales citados en esta reseña, es el más sencillo. Primero, el niño debe escoger "crear una nueva película" - o ver una ya creada en caso de que quiera visionar alguna- y aparecerá el entorno virtual de un software de edición. El sistema pide entonces, arrastrar los clips de vídeo que ya están pregrabados e inspirados en la verdadera vida de los animales, hasta la Línea de Tiempo. Posteriormente, ha de agregar en la banda del Timeline que corresponda, los sonidos de animales que ofrece la segunda columna. Lo mismo puede hacer con la música, arrastrar el clip hasta la banda adecuada. Y por último, el pequeño director debe escribir los rótulos que identificarán los clips que desee, por ejemplo “Animales de la selva”. Basta con pulsar el botón “play” en el monitor y podrá ver la producción completa. ¡Es todo! 


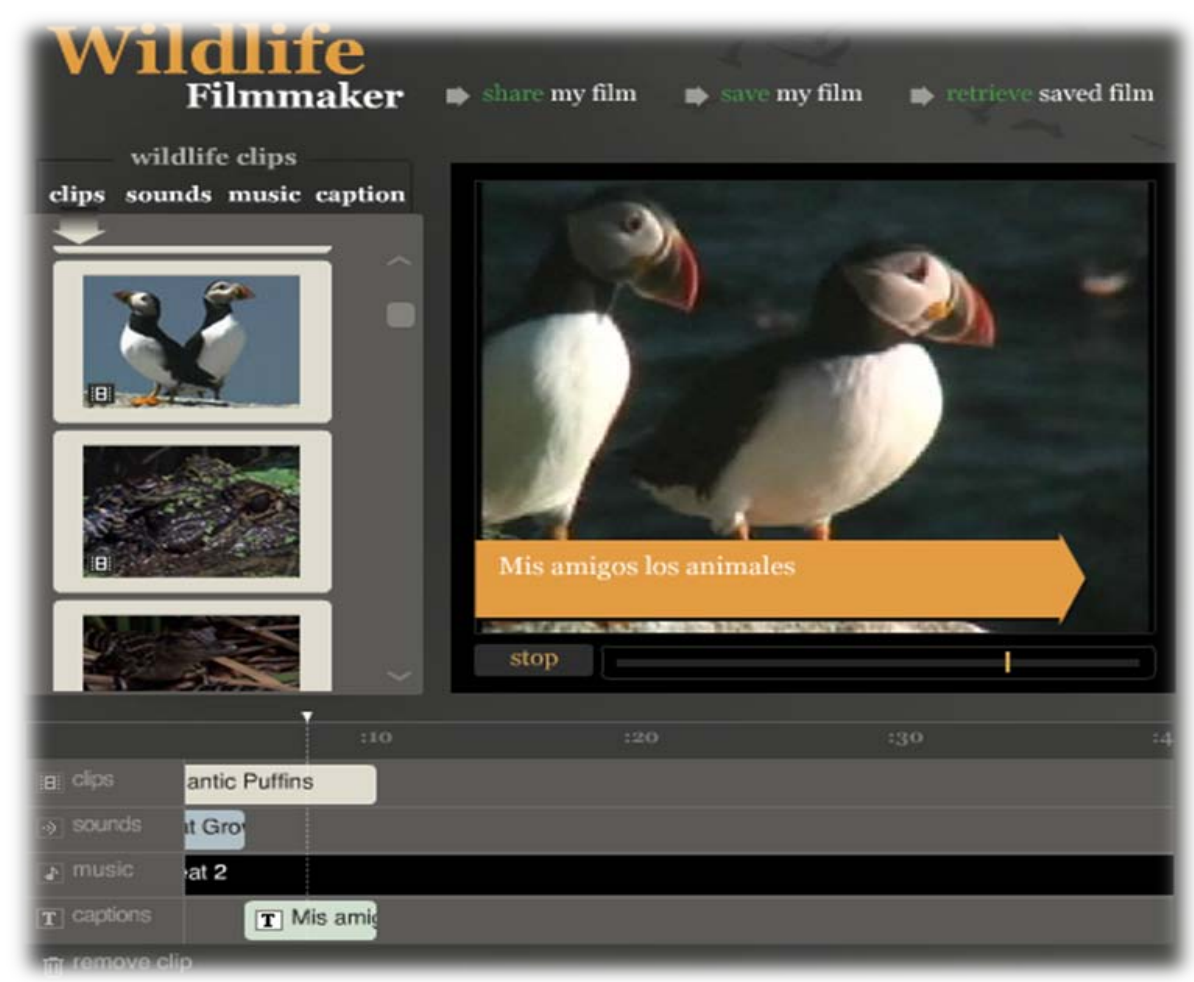

Si comete algún error puede remover el clip arrastrándolo hasta la papelera que aparece en el extreme inferior de la ventana. El niño puede grabar el resultado final con dos finalidades: para compartirlo en la Red a través del correo electrónico y las redes sociales u obteniendo un código para recuperarlo posteriormente en cualquier otra sesión. De este modo otros usuarios pueden ver la película cuando deseen. Resulta fascinante visionar un pequeño documental creado son imágenes verdaderas, grabadas por profesionales de excepción como los de National Geographic.

\section{Conclusión}

El documento audiovisual producido por niños y adolescentes se encuentra todavía disperso en experiencias -aisladas en su mayoría- con las que centros docentes o talleres infantiles participan en eventos o utilizan alguna que otra práctica novedosa en el aula. En países como Canadá y Australia estas prácticas ya están implantadas en las actividades escolares y no son ningún acontecimiento. No obstante, la Red provee una profusa documentación sobre cómo se produce un material audiovisual destinada principalmente al adulto, al maestro o docente de los diversos niveles educativos. El niño y adolescente se ve entonces en la necesidad de buscar sus propios recursos 
preguntando a otros o a través del ensayo y error. Las redes sociales estimulan también a los menores a "subir” o “colgar” sus imágenes y vídeos en Internet, aún cuando éstos no sean conscientes ni del proceso ni de lo que supone publicar en Internet. De ahí que lo más conveniente es acercarnos a ellos, explicarles cómo se produce y alertarlos de los riesgos.

Ahora bien, el contacto con distintas instituciones que imparten cursos de cinematografía a los más jóvenes hace pensar que "el material de enseñanza es con frecuencia la propia voz del instructor. No utilizan ningún libro de texto en especial o sitio web en particular. La dinámica más asidua es hacer que el alumno vaya elaborando su propio cuaderno de trabajo” (Sánchez-Carrero, 2009: 178). Efectivamente, estamos todavía en un proceso de transición en el cual se editan y preparan recursos para la enseñanza audiovisual de niños y adolescentes. Sobre todo desde que el Parlamento Europeo declarara a finales de 2008 que la educación mediática habría de ser instaurada en el currículo escolar.

Por eso, estos tres ejemplos -Film Street, Zimmer Twins y Wildlife Filmmakerconforman un panorama alentador para quienes estudiamos e intentamos aportar y difundir recursos referentes a la alfabetización mediática. El medio audiovisual ha de ser un medio familiar, al que conozcamos de cerca, sin miedos. Al contrario, debemos educarnos para poder controlarlo y convertirnos en espectadores conscientes y activos. Es la única manera de formar a nuestros niños como receptores críticos.

\section{Referencias Bibliográficas}

REVUELTA, Francisco y PÉREZ, Lourdes (2009). Interactividad en los entornos de formación on-line. Barcelona: UOC.

SÁNCHEZ-CARRERO, Jacqueline (2008). Pequeños Directores: niños y adolescentes creadores de cine, vídeo y televisión. Sevilla: Aconcagua.

Actimedia (2009). Firstlight Films/Culture Online - Film Street. http://www.atticmedia.com/?p=138 [consulta: 30/06/2010]

Film Street: http://www.filmstreet.co.uk/thestreet/default.aspa [consulta: 23/01/2010] 
Zimmer Twins: http://www.zimmertwins.com/ [consulta: 30/06/2010]

Wildlife Filmmaker:

http://animals.nationalgeographic.com/animals/article/filmmaker.html [consulta: 30/06/2010]

Telekids: http://jsanchezcarrero.blogspot.com [consulta: 30/06/2010] 